\title{
The process of production of liquefied methane - the component of rocket propellant Anatoly M. Domashenko ${ }^{(\mathrm{a}, 1)}$, Andrey L. Dovbish ${ }^{(\mathrm{a}, 2)}$ \\ PJSC "Cryogenmash" \\ Balashikha, Moscow region, 143907, Russian Federation, \\ 1)domashenko@cryogenmash.ru, \\ 2) andrey_dovbish@cryogenmash.ru
}

\begin{abstract}
The use of new fuel components, such as LNG or liquefied methane, in rocketspace, aviation and other special-purpose engineering is promising. On the basis of these fuel components it is possible to provide a number of technical and tactical parameters of aircrafts, which are not achievable when using standard fuels.

Considered were the cryogenic systems developed by PJSC "Cryogenmash" for natural gas liquefaction with liquid methane recovery by the method of lowtemperature condensation, stage separation and rectification. The second method allows to reduce the content of not only low boiling but also high boiling liquids in methane liquefied.

Key words: cryogenic engineering, liquefied methane, liquefier, stage separation, rectification, rectification column.
\end{abstract}

\section{INTRODUCTION}

Leading cryogenic companies from the USA, China, Japan, Western Europe, as well as Russia, reasonably predict the use of liquefied methane (LM) as the main fuel for transport facilities of the XXI century, including special purpose equipment (aerospace, rocket-space, aviation) [1]. These facilities are widely used in the production and use of liquefied natural gas with the production volumes of less than $10 \mathrm{t} / \mathrm{h}$. PJSC "Cryogenmash" is a domestic leader in the production of LNG plants of a relatively low capacity [2].

In future, the use of LM in liquid-propellant rocket engines is envisaged [3]. For this purpose it is necessary to produce LM with at least $99 \%$ methane content in it. According to GOST R 56021-2014, such cryogenic fuel should correspond to grade A [4]. Production of LM of this grade, according to [5-7], is a rather complicated problem.

One of the important elements in ensuring reliability and safety is the development of cryogenic fuel handling procedure, which ensures their quality assurance at all process operations. Experience in handling LM as a fuel in Russia is not enough yet, although its use in road or rail transport is not a problem. The situation is much more serious with the development of LM handling procedure in space rocket systems, where strict requirements to fuel quality are imposed, and there is no real experience in domestic or foreign practice [4]. 
The definition of "strict requirements" to the quality of LM as to rocket fuel is mainly due to the high content of methane in LM (98-99,96\% mole), while the rest is ethane, propane, butane, pentane, nitrogen, oxygen, carbon dioxide (not more than $0,005 \%$ ).

Natural gas (NG) supplied for liquefaction usually has a composition in which the content of both methane (within 85-99\%) and impurities can vary in a wide range. Therefore, in order to meet the requirements of the standard to the parameters of LM as a component of rocket fuel, it is necessary, first of all, to develop the liquefaction plants, allowing to obtain the corresponding composition of LM and further to observe such LM handling procedure, so that in the process of its delivery from the plant to the product tank the content of impurities in the fuel did not exceed the range specified in the requirements of the said standard.

Methane recovery from NG can be carried out by various methods: lowtemperature condensation and separation, rectification, selective adsorption, using membrane technologies in gas separation plants.

When high concentrations of high boiling components are observed, a rectification process is used in which continuous mass and heat exchange between the liquid and gas streams moving towards each other is provided to increase the methane concentration. At that, the low boiling fraction while being evaporated, condenses the high boiling fractions and, while divesting from them, increases its concentration. As a result of the rectification, steam withdrawn from the top of the column is significantly enriched with a low-boiling component (up to $99.9999 \%$ ), and the liquid withdrawn from the bottom is highly boiling.

Further the possibility of development of low-tonnage LM production on the basis of NGV-refueling station (ADENYUR).

To recover methane by the method of low-temperature condensation and separation, a high-pressure throttle ejector unit with one precooling stage based on ADENYUR is used [8]. In ADENYUR (Fig. 1) the gas supplied from the gas pipeline is purified from the droplet liquid in the separator, and from the mechanical particles in the filters. Compressed gas up to $20-25 \mathrm{MPa}$ is cooled down in intermediate and end heat exchangers and directed to an adsorption drying unit where it is dried to absolute humidity corresponding to the moisture dew point temperature of minus $30^{\circ} \mathrm{C}$. After that, the $\mathrm{NG}$ enters the gas storage (high-pressure receivers), and then through the reducing unit it enters the fuelfilling columns. As we see on the block diagram, almost all the ADENYUR process equipment is used to ensure the operation of the LM unit.

After ADENYUR storage, gas is fed into the LM unit, where it is cooled down to 0 - plus $5^{\circ} \mathrm{C}$ in the pre-cooling unit due to the cold return flow. Dried (to the dew point of minus $90^{\circ} \mathrm{C}$ ) and purified of $\mathrm{CO} 2$ impurities (to the residual content of $\mathrm{CO} 2$ of no more than $50 \mathrm{ppm}$ ), the gas enters the liquefaction plant, wherein the gas is liquefied and separated into methane and fuel gas.

To provide gas pre-cooling at the level of minus $40^{\circ} \mathrm{C}$, in order to increase the efficiency of the throttle cycle, a refrigeration machine is included in the LM unit. After cryogenic processing, the liquefied pure methane is throttled by the throttling valve (ThV) into the LM storage tank(s) (for example, on the basis of 
LM block storage systems, type BSHP-50/0.6), and the formed vapors are returned to the unit, where they recuperate the cold and further are pumped by the compressor into the direct flow supplied to the suction of ADENYUR compressors.

In the thermodynamic calculation of the process diagrams, the recommendations on choosing the constant, conditionally constant and variable parameters were considered pursuant to [9].

The program of calculation of the certain diagram was developed with the use of standard modules, for example, the program for calculation of the substances thermophysical properties or specially developed sub-programs, namely: calculation of the processes (throttling, expansion process in the expander); linear systems solving; thermodynamic calculation of the processes of rectification of multi-component mixtures; calculation of multi-flow coil heat exchangers, which makes it possible to determine the temperature differences in the heights of heat exchangers and the required surface of heat exchange from the initial data obtained from the thermodynamic calculation of the diagram; auxiliary input-output subprograms.

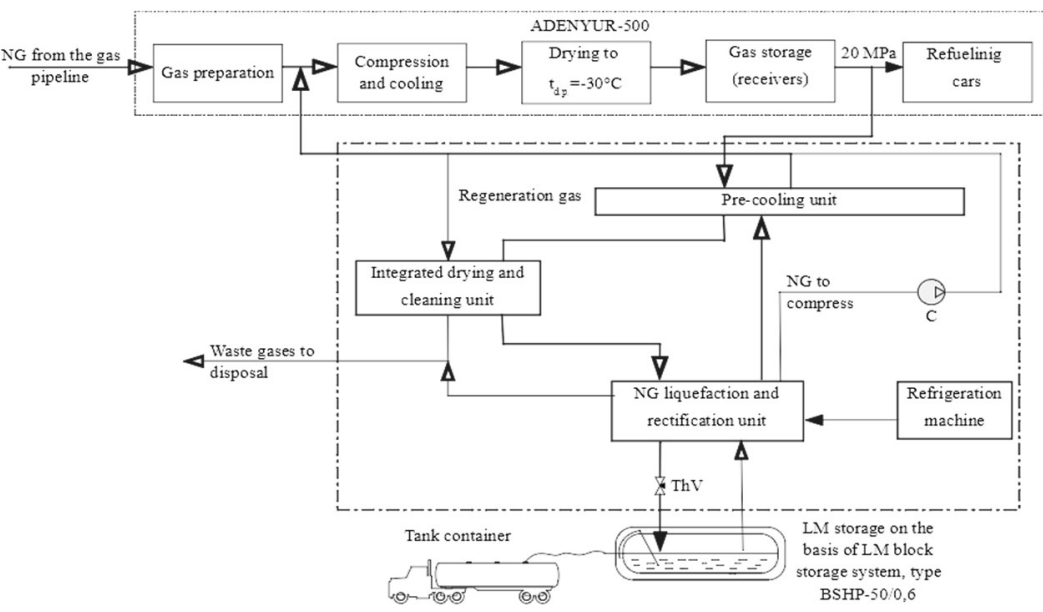

Fig. 1. The unit for a set composition liquefied methane production based on ADENYUR -500:

$$
\mathrm{C} \text { - compressor; } \mathrm{ThV} \text { - throttle valve }
$$

\section{The liquefaction plant provided with the separation unit}

The calculations prove that for gas processing with low content of heavy hydrocarbon fractions it is reasonable to use the circuit of high-pressure throttle ejector liquefier with pre-cooling without rectification columns, using only the effect of stage separation, to obtain liquefied methane. Fig. 2 shows the diagram of liquefaction of such a plant with preliminary Freon cooling and LM production by means of stage separation.

The ADENYUR compressors compress a mixture of gases, which is obtained by mixing the return flow from the liquefaction plant (p. 7) and the NG flow from the pipeline (p. 10). The purified and dried flow is fed to the inlet of the plant into the He-1 heat exchanger (p. 8), where it is cooled down by return flows 
(pp. 7 and 18). Further, the direct flow enters the evaporator (Ev) of Freon refrigerating machine (FRM) wherein it is cooled to the temperature of $238 \mathrm{~K}$ (p. 1). After the evaporator, the direct flow is fed to the inlet of the He-2 heat exchanger, wherein it is cooled by the return flows and, after leaving the $\mathrm{He}-2$, it is fed as an active flow to the inlet of the ejector, by means of which the vapors are pumped out of the intermediate separator S-2.

The ejector outlet flow (p. 3) enters the S-1 separator. Vapour flow from the S-1 separator (p. 5) enters the He-1 and He-2 heat exchangers as the main return flow. Liquid from S-1 is throttled into the intermediate separator S-2, wherein the pressure is $0.35-0.4 \mathrm{MPa}$. Vapours from the separator (p. 11) are fed to the inlet of the passive ejector nozzle and the liquid is throttled to the end separator S-3. The liquid from the S-3 separator is the purified LNG - liquefied methane (LM) of a given composition and is throttled into the liquid methane storage to the pressure of $0.14 \mathrm{MPa}$. The vapours from the S-3 separator, preheated in the He-2 and He-1 heat exchangers, are fed for disposal. With this flow (p. 18), nitrogen and oxygen are removed from the cycle.

The analysis of the overall balance of the plant shows that as a result of purification of LNG from low boiling components, the nitrogen concentration in the liquid decreases by about three times, the concentration of all high boiling liquids increases slightly due to evaporation of the liquid, and the concentration in the methane liquid increases by 0.004 molar fractions.

In the presence of components such as hydrogen and helium in the source gas, it is also necessary to use low-temperature blowing $[2,10]$.

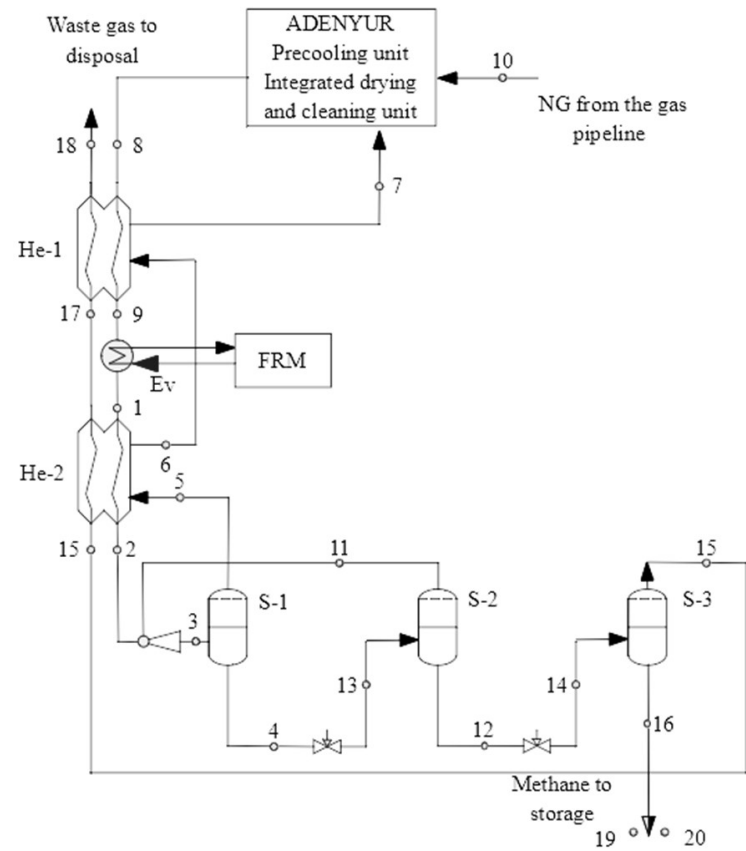

Fig. 2. Schematic design diagram of the liquefaction unit with natural gas separation unit 
The liquefaction plant with rectification unit

The analysis has shown that it is impossible to obtain high purity liquefied methane from natural gas by any of the given compositions without using rectification processes. On the basis of the data of preliminary calculations of various versions of the certain units for natural gas liquefaction and purification, a circuit for liquid pure methane production from natural gas was developed. Fig. 3 shows the plant schematic design diagram. Purified and dried natural gas (p. 2) enters the group of preliminary heat exchangers He-5 and He-6, after which it is cooled in the evaporator of the Freon refrigeration machine Ev-RM. Further the $\mathrm{NG}$ is cooled in He-1 and He-2 heat exchangers and Ev-1 evaporator of column RC-1.

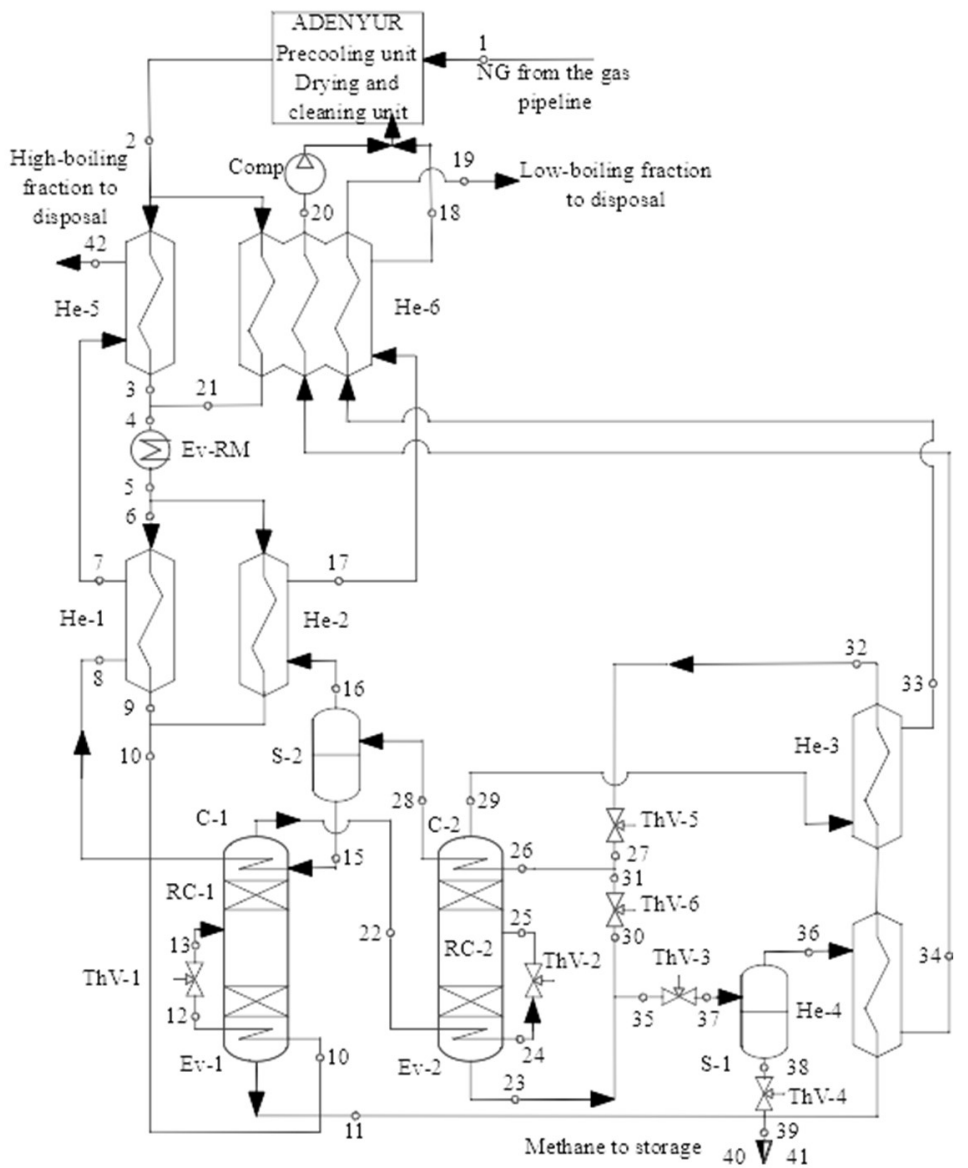

Fig. 3. Schematic design diagram of the liquefaction unit with natural gas rectification unit

After leaving Ev-1, NG is throttled in the valve ThV-1 to the pressure of 3.0 $\mathrm{MPa}$ and is fed to the column RC-1 for separation. Liquid enriched with highboiling components is withdrawn from the bottom part of the column (p. 11), while the vapour flow (p. 22), purified from heavy components (C2 plus the highest) and 
containing low-boiling components (nitrogen and oxygen) and methane leave the top part. Vapour flow (p. 22) enters the evaporator Ev-2 of column RC-2, wherein it is cooled and partially condensed. After Ev-2, the flow (t. 24) is throttled into ThV-2 to a pressure of $1.5 \mathrm{MPa}$ and is fed to the RC-2 column for separation. The choice of operating pressures in the separation columns is determined by the result of multiple calculations with different values of the varied data.

From the upper part of the column RC-2 withdrawn is the vapour flow (p. 29) enriched with low-boiling components, while the purified liquid methane is withdrawn from the lower part of the column (NG purification from high-boiling impurities was performed in the RC-1 column). The pure methane flow is throttled into ThV-3 to a pressure of $0.2 \mathrm{MPa}$, separated in a S-1 separator and delivered to a liquid methane storage facility (p.39). At the inlet to the storage, the liquid methane flow is throttled into ThV-4 to the pressure in the storage $(0.14$ $\mathrm{MPa}$ ) and is separated into the steam flow (p. 41) and the liquid that is drained into the storage (p. 40). Fluid from the RC-1 column (p. 11) is successively cooled in the He-4 heat exchanger by the vapour flow from the S-1 separator and in the He-3 heat exchanger by the vapour flow from the upper part of the RC-2 column. After the He-3 heat exchanger, the flow (p. 32) is throttled into the ThV-5 throttle to a pressure of $0.75 \mathrm{MPa}$, mixed with a portion of the pure methane flow (p. 31) and fed into the C-2 condenser of the RC-2 column (p. 26) as a coolant. After leaving the condenser $\mathrm{C}-2$, the flow is separated in the separator S-2 into vapor (p. 16) and liquid (p. 15) phases. The vapour phase (p. 16) preheated in the He-2 and He-6 heat exchangers is fed to the ADENYUR inlet. Liquid phase as a coolant enters the condenser C-1 of column RC-1. After leaving the condenser (p. 8), the flow is preheated in He-1 and He-5 heat exchangers and fed for disposal (p. 42). The highboiling components of natural gas are removed from the cycle with this flow.

The vapour flow from the top part of RC-2 column is preheated in series into He-3 and He-6 heat exchangers and enter for disposal (p. 19). With this flow, low-boiling components are withdrawn from the circuit. The vapour flow from the S-1 separator (p. 36) is heated in series in the He-4 and He-6 heat exchangers and after being compressed in the compressor (Comp) is fed to the ADENYUR. Each initial composition will have specific parameter values at all points in the circuit. The differences will be mainly in the amount of flows to be disposed.

\section{The material balances of the plant with the NG rectification unit}

From the overall design balance of the plant with rectification columns, it is evident from processing the gas of composition (B) that the developed process makes it possible to recover almost pure methane (0.9997) from LNG.

In Table 1 given are the basic values of technical characteristics of the unit for production of liquefied methane of specified composition.

The analysis of specific power consumption for liquid methane production is of particular interest (Table 1). Consumption rises simultaneously with the increase in the amount of low-boiling and high-boiling impurities, because some portion of methane is withdrawn together with the latter, which results in reduction of the plant performance. 


\begin{tabular}{|c|c|c|c|}
\hline \multirow[b]{2}{*}{$\begin{array}{l}\text { Parameters and } \\
\text { dimensions }\end{array}$} & \multicolumn{3}{|c|}{ Values } \\
\hline & $\begin{array}{l}\text { The version of } \\
\text { the unit } \\
\text { diagram } \\
\text { without } \\
\text { rectification } \\
\text { unit when } \\
\text { composition } \\
\text { "A" NG is } \\
\text { processed }\end{array}$ & $\begin{array}{l}\text { The version of } \\
\text { the unit diagram } \\
\text { with rectification } \\
\text { unit when } \\
\text { composition "A" } \\
\text { NG is processed }\end{array}$ & $\begin{array}{l}\text { The version of } \\
\text { the unit diagram } \\
\text { with rectification } \\
\text { unit when } \\
\text { composition "B" } \\
\text { NG is processed }\end{array}$ \\
\hline 1 & 2 & 3 & 4 \\
\hline $\begin{array}{l}\text { 1. Amount of gas } \\
\text { supplied for processing } \\
\text { from the pipeline, } \mathrm{Nm}^{3} / \mathrm{h} \\
(\mathrm{kg} / \mathrm{h})\end{array}$ & $\begin{array}{c}1408,1 \\
(1024,3)\end{array}$ & $\begin{array}{c}1229,8 \\
(894,56)\end{array}$ & $\begin{array}{c}1787 \\
(1469,2)\end{array}$ \\
\hline $\begin{array}{l}\text { 2. Amount of gas } \\
\text { enriched with low- } \\
\text { boiling components to } \\
\text { be disposed, } \mathrm{Nm}^{3} / \mathrm{h} \\
(\mathrm{kg} / \mathrm{h})\end{array}$ & $\begin{array}{c}143,7 \\
(106,95)\end{array}$ & $\begin{array}{c}42,7 \\
(35,94)\end{array}$ & $\begin{array}{c}486 \\
(435,5)\end{array}$ \\
\hline $\begin{array}{l}\text { 3. Amount of gas } \\
\text { enriched with high- } \\
\text { boiling components to } \\
\text { be disposed, } \mathrm{Nm}^{3} / \mathrm{h} \\
(\mathrm{kg} / \mathrm{h})\end{array}$ & - & $\begin{array}{l}32,15 \\
(31,6)\end{array}$ & $\begin{array}{c}523,6 \\
(474,2)\end{array}$ \\
\hline $\begin{array}{l}\text { 4. Compressors total } \\
\text { power, } \mathrm{kW}\end{array}$ & 750 & 750 & 750 \\
\hline $\begin{array}{l}\text { 5. Specific power } \\
\text { consumption for liquid } \\
\text { methane production, } \\
\mathrm{kW} \cdot \mathrm{h} / \mathrm{kg} \text { of liquid } \\
\text { methane }\end{array}$ & 0,8232 & 0,9387 & 1,394 \\
\hline $\begin{array}{l}\text { 6. Methane content in } \\
\text { LM, mole fraction }\end{array}$ & 0.98893 & 0.99989 & 0.99972 \\
\hline
\end{tabular}

Table 1. The analysis of specific power consumption for liquid methane production

\section{CONCLUSIONS}

1. For LM plants of capacity of up to $1 \mathrm{t} / \mathrm{h}$ it is reasonable to use the plants on the basis of the throttle-ejector cycle with pre-cooling as the easiest to operate and having good specific power parameters and operating experience [2].

2. To produce liquefied methane of a specified composition from natural gas with a low content of heavy hydrocarbon fractions, it is advisable to use throttle-ejector liquefier circuits with LNG pre-cooling and staged separation. 
3. When developing a unified circuit for liquid methane production using almost any natural gas, it is necessary to use the plants with rectification columns.

4. It has been shown that the developed LM plants can produce liquefied methane for liquid propulsors, power plants, ships, planes, gas-turbine locomotives.

\section{REFERENCES}

1. A.M. Domashenko, V.N. Krishtal, A.G. Lapshin, A.L. Dovbish, et al.,Cryogenic equipment for production, storage, transportation of the natural gas in the liquefied condition, Transport and underground gas storage, 3 (2008)

2. A.L. Dovbish, V.A. Peredelskiy, K.V. Bezrukov, et al.,Industrial gases, 2 (2012)

3. G.K. Lavrenchenko, Actual problems of production and use of $C N G$ and $L N G$, Industrial gases, 3 (2012)

4. GOST R 56021-2014. Combustible natural liquefied gas. Fuel for internal combustion engines and power plants. Specifications.

5. A.M. Domashenko, Yu.V. Kondrashkov, The procedure for quality assurance of the liquefied methane fuel for the rocket and space complexes, Chem. and petroleum eng., 11 (2003)

6. S.P. Gorbachev, I.S. Medvedkov, Industrial gases, 4 (2012)

7. S.P. Gorbachev, I.S. Medvedkov, Specific features of the small-capacity LNG production on the gas pipelines on the basis of the high-pressure throttle cycles, Industrial gases, 1 (2016)

8. I.F. Kuzmenko, A.L. Dovbish, V.A. Peredelsky, A.I. Lyapin, S.G. Serdyukov, Improvement of the efficiency of the small-capacity natural gas liquefaction plants, Chem. and petroleum eng., 5 (2002)

9. A.M. Arkharov, Fundamentals of Cryology. Anthropy-statistical analysis of lowtemperature systems (2014)

10. Patent RU, № 2355959. The method of extraction of natural gas low-boiling components during its liquefaction in a closed loop and installation for its implementation. 